\title{
Complex and Troublesome Relations
}

\section{VICTORIA ESTEVES}

UNIVERSITY OF STIRLING

Dan Hunter, Ramon Lobato, Megan Richardson and Julian Thomas (eds)

Amateur Media: Social, Cultural and Legal Perspectives

Routledge, Oxford, 2012

ISBN 9780415782654

RRP $£ 85.00$

Amateur Media is a very relevant book that takes into careful consideration different aspects of the current media landscape and its relationship with amateur users, as well as legal problems that may arise. The volume brings forth a variety of scenarios that accurately translate the complex liaison between formal and informal aspects of media production, as well as law's attempt to accommodate these changes. It is composed of eighteen interrelated chapters, divided into six parts. It is structured around a key text in each part, to which the two subsequent chapters add and respond. 
Part I deals with issues of economic histories. In chapter one, Lobato, Thomas and Hunter dispel the idea of user-generated content (UGC)/'producer media' antagonism, and introduce the formality spectrum as a refreshing framework for looking at UGC/professional (inter)relations. Different aspects fall in different parts of the formality spectrum at different times, making these media activities and products harder to categorise. By unveiling the flexibility that exists within the formality spectrum, similarities between different forms of media become apparent, further dispelling the dichotomy between professional/UGC. Formality and informality enmesh, creating a fluid notion of UGC. The authors embrace the importance-and penetrability-of informality within media economies and criticise the inability of governments to recognise this, an oversight which has translated into the creation of shortsighted and unfit legislative measures regarding informal forms of media.

In the second chapter, Richardson and Goldenfein point out the oppressive regulations outlined in chapter one have had a counter-productive effect on informal economies. They accuse law of being biased towards regulatory bodies instead of informal media (in the case of Wikileaks, for example). The conclusions of chapter one are developed further as Richardson and Goldenfein demonstrate how successful formal media economies are built on underlying informal structures. These structures, in turn, are based on illegal predecessors such as Napster, organisations that have disregarded intellectual property rights, yet have many common parallels with convergent media corporate giants such as Apple. Yet the authors of this chapter also point to court cases that hint towards a positive accommodation of informality within law. Their argument raises the relevant question of whether we are witnessing the early stages of change regarding firmly rooted legal stances when it comes to amateur content, but I believe further evidence is needed before one can extrapolate results.

The co-existence of formality and informality online is noted in chapter three. Quiggin shows how the internet has reversed twentieth-century trends in household economics, effectively shifting what were exclusively professional roles onto amateur users. The author offers an effective analysis of UGC economics, but it could have been further enhanced by referring to the framework of participation that underlies the internet, since this newfound framework has contributed to the 
reversal of established economic trends that Quiggin mentions. Quiggin suggests the household and gift exchange economies that occur online need to have a category of their own, urging for the analysis of online economies to not rely on (inadequate) offline categories.

Part 2 of the book deals with the topic of platform politics. In chapter four Hetcher, determined to dispel set notions of amateur culture, delves into its commercial aspect. It's a tense relationship, as fears regarding amateur authenticity arise in commercial contexts. Yet Hetcher underlines the importance of commercialism for the survival of amateur content. Despite Keen's and Lanier's critiques, Hetcher recognises the value of creating UGC. Confronted with the pivotal Viacom v. Youtube case, Hetcher questions whether Youtube should control uploaded content, and acknowledges Youtube's ever-growing non-infringing videos as having creative, social and cultural value. The case marked Youtube's importance in legal precedents in this area and the decision in favour of Youtube gives hope to amateur culture.

The fifth chapter shows that Youtube's business models have further clouded the distinction between amateur and professional media. Burgess uses the 'Partner Program' to exemplify how Youtube has harnessed the power and allure of amateur videos and has progressively professionalised, formalised and monetised them. She speaks of other measures Youtube has taken guide its uploaders towards noninfringing uses (for example, 'Youtube Playbook' and automated takedown) and raises the pressing question of how these measures may be a threat to the remix culture prevalent in Youtube and amateur reappropriation of culture in general.

Chapter six covers the convoluted relationship between commercialism and amateur content. Weatherall fears commercial pressures shape amateur content, a concern raised throughout history about commercialisation of art. Financial reward as a substitute motivation for altruism might discourage true amateur enthusiasts to participate, explaining amateurs' reluctance to embrace commercialism. Weatherall's comparison of amateur videos with art translates their undeniable value in our current media economy. Weatherall also accuses legal notions of UGC to be misrepresentative and out-dated, portraying it as an inferior activity, which cripples its protection in terms of copyright. She warns about the dangers of 
Youtube's anti-copyright enforcement and its effects on orphan works and creativity.

The three chapters in Part 3 turn to the issue of amateurs and authenticity within current media. Bowrey focuses on the authenticity in MasterChef in chapter seven. The author raises the issues of the difficulty in copyrighting the format and free labour, exposing the diversion created in order to mask oppressive plays of power, an interesting addition to Andrejevic's work. ${ }^{1}$ Advertising is also masked, as MasterChefblends product placement seamlessly with the action. Bowrey denounces poignant issues that shadow this type of marketing: a distressing lack of governmental regulation and the emotional manipulative effect. Still, MasterChef engages audiences to participate within convergent media. Bowrey delivers a cautionary warning about the potential abuse of power (and how law facilitates this) within corporate media.

In chapter eight, David Tan focuses on fair use policies regarding the Harry Potter franchise, echoing the critique that copyright law needs to be modernised to fit remix media reality. Tan aptly indicates that amateur use of copyright-protected characters in fan-fiction does not compete with its canonical counterparts and suggests law must abandon its reductive (and at times non-existent) view of fan work as it holds cultural, transformative and empowering characteristics. The establishment of the importance of fan work in this chapter echoes Henry Jenkins' work. $^{2}$

Trabsky uses Baudrillard's simulacra in chapter nine to address questions of authenticity in T-Mobile's Flash Mob advertisement. Trabsky denounces professional manipulation of an amateur event for the purposes of corporate interest, extending on Bowrey's aforementioned marketing strategies that target consumers in novel unexpected forms. Trabsky identifies the elements that propel this fabricated impulsiveness: cinematography and reliance on the association of flash mobs with amateur spontaneity. Despite admitting its fabrication, the advertisement holds a delicate tension between amateur and professional, real and simulated. Trabsky fittingly criticises it as a Baudrillardian nightmare, where corporations poach amateur modes of expression to increase profits.

Part 4 presents three chapters about the existing issues and tensions within cultural intermediaries. The intricacies of amateur-professional relations within 
music journalism are addressed in chapter ten. Lobato and Fletcher's claims for music journalism's (growing) deprofessionalisation echo Quiggin's 'reverse' household economy trends. Although practiced by amateurs outside formal settings, it's driven by professional standards in an ever-growing fragmented digital landscape. The authors describe how online patterns of these cultural intermediaries contain both the informative job of trade papers and the serious music commentary of music magazines. Yet there is an intermixing of both styles online, perpetuating the book's narrative of amateur/professional media convergence. A reductive view of blogs is dismissed as they are part of the fabric of music journalism, their 'amateur media' label complicated, since they can be entrepreneurial. The authors are alert to the unsettling condition music journalists endure (explored later by Hesmondhalgh).

In chapter eleven, Wirtén studies Swedish fansubbers (amateurs who produce their own subtitled versions of existing films or videos) and their implicit codes of conduct. Here it is implied that these results can be extrapolated to other fandoms. Jenkins' and Rembert-Lang's work would have been interesting additions here, but Wirtén manages to tackle the underexplored world of fan-to-fan work, while placing this online example within the larger frame of historical tension about translation, copyright and authorisation. ${ }^{3}$ Wirtén translates the ironic defensiveness fansubbers feel towards their work, reminding us that their work is a violation of copyright law. She also underlines the effort that amateurs put into their fansubbing, echoing chapter ten's ethos of high quality standards in an amateur environment.

Hesmondhalgh approaches a topic in chapter twelve that is largely overlooked: working conditions within media and cultural settings. He raises the problems of prevalent free labour economy present in amateur media, as well as applying his previous framework of good and bad work to cultural industries. He exposes the 'dark' side of online participatory culture: devaluated non-paid work that can be-as Mark Andrejavic has commented-exploitative. ${ }^{4}$ Not only is this exploitation acceptable and expected but many times it is self-induced. There is also a dangerous blending of work and leisure within the creative industries, leading to overwork in an unstable environment.

The relationship between games (and game-related fandoms) and intellectual property is addressed in the three chapters that make up Part 5. In the thirteenth 
chapter, Lastowka deals with issues of property and play in Minecraft, revealing the impact of (and on) Web 2.0 as a contemporary concept that captures the current online atmosphere of democratic participation; an environment where everyone is as much of a consumer as a creator. Lastowka explains Web 2.0 through pertinent writers (Lessig, Shirky, Jenkins), demonstrating an understanding of the current digital environment. He establishes the games' undeniable creative and amateur origins as well as their intermixing of the amateur and professional. Indie yet professionalised, Minecraft encourages user creativity within and beyond the game, demonstrating users' reliance on Web 2.0 to share their creations, sparking wide amateur participation. Minecraft seems to embody the Web 2.0 ethos described by O’Reilly, Meikle and Young and Lessig. ${ }^{5}$ Lastowka recognises the game's harnessing of amateur creativity as a large part of its success, but criticises the inadequate and outdated legal stances (especially regarding copyright and intellectual property law) that are applied to the current Web 2.0 atmosphere and exposes law's repressive control over digital content. Lastowka recognises how this repressive stance might stifle UGC creations that are built on existing professional content. Despite legal barriers impairing amateur-professional relations, Minecraft's minimal approach to copyright hints at changes in gaming's intellectual property.

In chapter 14, De Zwart demonstrates how cosplay is a participative expression of amateur creativity that works as an extension of digital games/gaming culture. The importance of amateur creation is translated in cosplay conventions' rejection of professionally made outfits; being an ephemeral event, cosplaying also relies on amateur participation online for its proliferation, demonstrating the importance of Web 2.0. De Zwart successfully draws on Jenkins' work of fan engagement. She denotes a more relaxed legal approach to amateur cosplay, which works as free publicity. Interesting questions about authorship arise within this context, as cosplayers bring bound text to life.

McCrea then builds on Lastowka's recognition in chapter fifteen of the importance of amateurs within digital gaming development, signalling the importance of the subculture of amateur game design and its impact (and importance) on professional game design. McCrea exposes the professional gaming industry's antagonist view of Web 2.0, aiding Lastowka's claim of the professional industry's reluctance to embrace amateur creativity fully. McCrea also demonstrates 
how the commercial success that is Minecraft builds on the success of previous amateur games. Despite its commercialism, Minecraft retains the indie ethos that underlies its predecessors, and stands as a piece of what McCrea calls 'Web Zero' resistance.

Lastly, Part 6 approaches the often complex and troublesome relationship between anonymity, identity and publicity that exists in the convergent media environment. Chapter sixteen focuses on legal aspects of anonymity and online speech. It signals the increasing importance of and dependence on internet communication, recognising many amateurs are not legally prepared for its intricacies. Murchison draws on differing cases, focusing on bloggers' liability, (lack of) identity and rejection of journalistic norms, the ineffective consequences of counter-speech, reliance on old methods for new media and protection of blogger anonymity. Throughout, Murchison describes the continuous struggle between freedom of speech and right to privacy that echoes Solove. ${ }^{6}$ Despite being comprehensive, the author at times relies too much on the readers' knowledge of technical legal terms and history.

In chapter seventeen Austin picks up on anonymity and privacy. However, she moves beyond the private-public dichotomy offered by Murchison and offers a more complex alternative involving audience segregation. She successfully uses Goffman's self-presentation theory, noting that regarding (anonymous) internet interactions one must keep in mind both audience and context. Continuing legal critiques, this section also points out law's inadequacy concerning views of privacy and anonymity-which appear to lack sensitivity to the Web 2.0 atmosphere.

The last chapter tackles the issue of what privacy might expect to have in social media, and draws parallells between an Australian case and those discussed in chapter sixteen. Richardson and Thomas expose the tendency of courts of law to view all online spaces as openly public, shrugging the law's responsibility towards amateur anonymous users. They also draw parallels between law's reluctance to protect writers' anonymity throughout history and attitudes taken towards anonymous bloggers nowadays. The authors reminds us of the value and purpose of anonymous writing as central to free speech without fear of repercussions-though they also exposes the downside of it. 
In conclusion, Hunter, Lobato, Richardson and Thomas present a different framework for user-generated content and new media, expose existing problems from a legal perspective and effectively explore the complex interrelation between amateur and professional media. By establishing parallels with older examples, the collection helps de-mystify digital media by placing it within the realm of media historical continuity. Nevertheless, it also makes a point of decrying a lack of adequate measures and attitudes-especially legal—towards new forms of media interaction. Hopefully this text will mark the beginning of a trend that refuses to oversimplify and reduce amateur media and instead upholds its value within society.

Victoria Esteves is a PhD student at the University of Stirling. She currently teaches 'Digital Media and Culture' and 'Digital Cultures' at the University of Stirling's School of Arts and Humanities. Her research focuses on the circulation of participatory culture online.

\section{-NOTES}

${ }^{1}$ Mark Andrejevic, 'Exploitation in the Data Mine' in Internet and Surveillance: The Challenges of Web 2.0 and Social Media, ed. Christian Fuchs, Kees Boersma, Anders Albrechtslund and Marisol Sandoval, Routledge, New York, 2012, pp. 71-88 and Reality TV: The Work of Being Watched, Rowman \& Littlefield Publishers, Lanham, 2004.

${ }^{2}$ Henry Jenkins, Convergence Culture: Where Old and New Media Collide, New York Press, New York, 2006 and Textual Poachers: Television Fans \& Participatory Culture, Routledge, New York, 1992.

3 Jenkins, Convergence Culture and Textual Poachers; LaToya D. Rembert-Lang, 'Reinforcing the Tower of Babel: The Impact of Copyright Law on Fansubbing', Intellectual Property Brief 2, no. 2, 2010, pp. 2133.

${ }^{4}$ Andrejevic, 'Exploitation in the Data Mine'.

5 Tim O'Reilly, What Is Web 2.0? 30 November 2005, <http://oreilly.com/web2/archive/what-is-web20.html> (accessed 15 November 2012); Graham Meikle and Sherman Young, Media Convergence: Networked Digital Media in Everyday Life, Palgrave Macmillan, Basingstoke, 2012; Lawrence Lessig, Remix: Making Art and Commerce Thrive in the Hybrid Economy, A\&C Black, London, 2009.

6 Daniel J. Solove, The Future of Reputation: Gossip, Rumor, and Privacy on the Internet, Yale University Press, London, 2007. 